\title{
Chemotherapeutic control of Gram-positive infection in white sea bream (Diplodus sargus, Linnaeus 1758) broodstock
}

\author{
Nadia G. M. Ali ${ }^{1}$, Ibrahim M. Aboyadak ${ }^{1}$ and Heba S. El-Sayed ${ }^{2}$
}

1. Fish Disease Laboratory, National Institute of Oceanography and Fisheries, Egypt; 2. Fish Reproduction Laboratory (Marine Hatchery), National Institute of Oceanography and Fisheries, Egypt.

Corresponding author: Nadia G. M. Ali, e-mail: nadiagabrali@gmail.com

Co-authors: IMA: i.aboyadak@gmail.com, HSE: hebasaad2222@yahoo.com

Received: 27-10-2018, Accepted: 22-01-2019, Published online: 23-02-2019

doi: 10.14202/vetworld.2019.316-324 How to cite this article: Ali NGM, Aboyadak IM, El-Sayed HS (2019) Chemotherapeutic control of Gram-positive infection in white sea bream (Diplodus sargus, Linnaeus 1758) broodstock, Veterinary World, 12(2): 316-324.

\begin{abstract}
Aim: This study aimed to identify the pathogenic bacteria responsible for the septicemic disease affecting white sea bream brooders and determining the sensitivity of the recovered isolates to different antibiotics followed by estimation of longacting oxytetracycline (OTC) efficacy in controlling this disease, and finally, determining the proper dose regimen.
\end{abstract}

Materials and Methods: Biolog microbial identification system was used for determination of the pathogens which are responsible for this disease. Agar disk diffusion test and minimum inhibitory concentration (MIC) were used to determine the antibiotic susceptibility of recovered isolates. Oxytetracycline (OTC) was used at a dose level of $100 \mathrm{mg} / \mathrm{kg}$ body weight for the treatment of diseased fish, and the OTC concentration in the serum samples was determined by high-performance liquid chromatography.

Results: Fifteen Staphylococcus epidermidis and 11 Bacillus cereus isolates were recovered from the lesion of muscle, tail, eye, and heart blood. S. epidermidis isolates were sensitive to OTC, ciprofloxacin, enrofloxacin, spiramycin, erythromycin (E), and florfenicol. B. cereus isolates were sensitive to all mentioned antibiotics except E. Based on the MIC test, all $B$. cereus isolates were sensitive to OTC with MIC ranging between $<0.125$ and $4 \mu \mathrm{g} / \mathrm{ml}$ and $11 \mathrm{~S}$. epidermidis isolates were sensitive with MIC ranging between $<0.125$ and $8 \mu \mathrm{g} / \mathrm{ml}$, while four isolates were resistant. Different degrees of degenerative changes were present in the hepatopancreas, posterior kidney, eye, and skin tissues of diseased fish.

Conclusion: Single intraperitoneal injection of long-acting OTC at a dose of $100 \mathrm{mg} / \mathrm{kg}$ body weight was effective in termination of $S$. epidermidis and B. cereus infection in white sea bream (D. sargus) broodstock.

Keywords: Bacillus cereus, histopathology, high-performance liquid chromatography, oxytetracycline, sensitivity, Staphylococcus epidermidis.

\section{Introduction}

Aquaculture is one of the fastest growing animal production sectors worldwide, where farmed finfish production rate has increased from 27.6 to 52.3 million (nearly duplicated) over the past decade from 2005 to 2015 [1]. Aquaculture is considered as an imperative choice to provide cheap animal protein for the growing world population. The global fishery production for human consumption reached 76 million tons in 2015. The aquaculture production is expected to exceed the fishery production by $1.36 \%$ fold at 2025 [2].

Expansion in marine aquaculture is an urgent priority for the Egyptian government, so it launched the largest maricultural farm in the Middle East at Berket Ghalioun. It targeted to culture about 5460 hectares with different marine fish species, and so there is a need for diversification and introduction

Copyright: Ali, et al. Open Access. This article is distributed under the terms of the Creative Commons Attribution 4.0 International License (http://creativecommons.org/licenses/by/4.0/), which permits unrestricted use, distribution, and reproduction in any medium, provided you give appropriate credit to the original author(s) and the source, provide a link to the Creative Commons license, and indicate if changes were made. The Creative Commons Public Domain Dedication waiver (http://creativecommons.org/ publicdomain/zero/1.0/) applies to the data made available in this article, unless otherwise stated. of new species. White sea bream (Diplodus sargus) is considered a good candidate for aquaculture as it has a high commercial value and good acceptability by consumers [3]. It is also an omnivorous fish and, therefore, needs fewer nutritional requirements in comparison to other Sparidae [4].

Bacterial diseases are the most dominant pathogens that are responsible for severe diseases and outbreaks in marine-cultured fish $[5,6]$. Most of the bacterial disease etiological agents are considered a part of the normal flora that is present in water, stress condition as bad water quality, inadequate diet, overcrowding, and frequent handling during artificial spawning are considered to be predisposing factors of lowering fish immunity and subsequently initiating disease conditions [7,8]. Streptococcus spp., Lactococcus garvieae, Staphylococcus epidermidis, and Micrococcus luteus are among the most common Gram-positive bacterial infection of cultured marine fish $[9,10]$, while vibriosis is the most Gram-negative bacterial infection [11-13].

Route of drug administration is a limiting factor that plays a considerable role in the success or failure of a treatment process, as it greatly affects the drug pharmacokinetic parameters including absorption, 
distribution, biotransformation, and excretion [14]. Intraperitoneal and intravenous drug administration provides not only the maximum bioavailability but also allows the drug to reach the site of infection very rapidly achieving high serum level [15], as well. Drug formulation has a vital role in the dosage regimen (frequency of application), i.e., long-acting preparations provide sustainable drug release in treated animal serum, which allow long-lasting effect that may extend for several days [16].

Broodstocks are extremely valuable and expensive fish. It requires a long time and effort for preparation; loss of any brooder fish is equal to the loss of thousands of produced fry each season, and so control of broodstock diseases is considered a priority for sustainable aquaculture.

This study aimed to identify the pathogenic bacteria responsible for the septicemic disease affecting white sea bream brooders and determining the sensitivity of the recovered isolates to different antibiotics followed by estimation of long-acting oxytetracycline (OTC) efficacy in controlling this disease, and finally, determining the proper dose regimen.

\section{Materials and Methods}

\section{Ethical approval}

Fish used in the current research were handled, transported, examined, and treated following the guidelines of the National Advisory Committee for Laboratory Animal Research (NACLAR) [17] and CCAC [18] regarding the care and use of fish in research, teaching, and testing which were approved by the National Institute of Oceanography and Fisheries (NIOF) Ethical Committee, Egypt.

\section{Study location}

The present work was conducted in the marine hatchery, NIOF, Alexandria, located at longitude $31^{\circ} 12^{\prime} 44.8^{\prime \prime} \mathrm{N}$ and latitude $29^{\circ} 53^{\prime} 05.1^{\prime \prime} \mathrm{E}$.

\section{Fish specimens}

Sixty white sea bream (D. sargus, Linnaeus 1758) broodstocks were examined through clinical examination. Of them, 23 were dead and moribund fish were used for postmortem, bacteriological, and histopathological examination. 20 clinically diseased fish were used in the treatment trial, and 10 healthy fish were used for the determination of antibiotic concentration in their serum. Fish ranged between 210 and $587 \mathrm{~g}$ in body weight and $16-28 \mathrm{~cm}$ in total length.

\section{Antemortem and postmortem inspection}

Antemortem and postmortem examinations were done as described by Stoskopf [19] for the detection of any changes in fish behavior or appearance also for the determination of any gross abnormalities in internal organs.

\section{Isolation of bacterial etiological agent}

It was performed as described by Aboyadak et al. [20], in which five samples were taken from each fish (tail lesions, muscle lesions, eye lesions if present, hepatopancreas, and heart blood). Each sample was individually inoculated to Tryptic Soy Broth for $12 \mathrm{~h}$, then streaked on tryptic soy agar $\left(\mathrm{Oxoid}^{\circledR}\right)$, and incubated at $33^{\circ} \mathrm{C}$ for $18-24 \mathrm{~h}$.

\section{Identification of the isolated strains using biolog system}

Few colonies from each recovered isolate were smeared on a glass slide and stained with Gram stain following the procedures mentioned by Black and Black [21].

Biolog microbial identification system (Biolog Inc., Hayward, CA, USA) is an automated, accurate, and rapid identification method that is based on carbon source utilization assay as each microorganism has a phenotypic fingerprint. GEN III MicroPlate has 12 columns each of eight rows: The first nine columns are for 71 carbon source utilization assays and the rest 3 columns for 23 chemical sensitivity assays. The utilization of carbon sources and resistance to the inhibitory chemicals were determined through tetrazolium redox dye.

A surface area of about $3 \mathrm{~mm}$ in diameter from the pure isolate that was grown on Tryptic Soy Agar was picked up using a cotton-tipped inoculator's swab. The swap was transferred and suspended in a special clean tube containing inoculating fluid. The turbidity was measured and adjusted to $95 \%$ using turbidimeter. After that, the bacterial cell suspension was poured into Biolog GEN III Microplates using the multichannel pipette. The inoculated microplate was covered with its lid and placed for incubation, and the result of the monitoring was logged in the OmniLog system.

\section{Histopathological examination}

The histopathological examination was carried out according to Suvarna et al. [22]. Tissue specimens from the hepatopancreas, posterior kidney, skin, and eye were fixed in $10 \%$ buffered formalin, dehydrated in ascending grade ethyl alcohol and cleared in xylene, sectioned to 4- $\mu \mathrm{m}$ thickness, mounted over a glass slide, and then stained with hematoxylin and eosin ( $\mathrm{H}$ and $\mathrm{E})$. Stained tissue sections were examined and photographed using Optika Microscope with a digital camera (Optika, Italy).

\section{Antibiotic susceptibility test}

Agar disk diffusion test was done to determine the sensitivity of the recovered bacterial isolates to OTC (OTC $30 \mu \mathrm{g}$ ), ciprofloxacin (CIP $5 \mu \mathrm{g}$ ), enrofloxacin (ENR $5 \mu \mathrm{g}$ ), florfenicol (F $10 \mu \mathrm{g}$ ), spiramycin (SP $100 \mu \mathrm{g}$ ), and erythromycin (E $15 \mu \mathrm{g}$ ) according to CLSI [23].

\section{Determination of the minimum inhibitory concentration (MIC) of OTC}

It was determined for all recovered isolates using broth macrodilution test according to Hack et al. [24].

\section{Preparation of ОTC standard solution}

About $10.66 \mu 1$ was pipetted from Alamycin $300^{\circledR}$ and made up to $1000 \mu \mathrm{l}$ with sterile distilled water 
to achieve a final concentration of $3.2 \mathrm{mg} / 1000 \mu \mathrm{l}$, and then, a double-fold serial dilution was done for 10 consecutive dilutions.

\section{Procedures}

The overnight growth of each bacterial isolate on tryptic soy broth was diluted and adjusted to 0.5 McFarland standard. After that, $0.5 \mathrm{ml}$ was added to $99.5 \mathrm{ml}$ sterile Mueller Hinton Broth, then $4.9 \mathrm{ml}$ was added to each of 11 sterile screw-caped, numbered test tubes followed by addition of $100 \mu \mathrm{l}$ from previously prepared OTC standard solution to the corresponding test tube to achieve a final concentration of $64,32,16,8$, $4,2,1,0.5,0.25$, and $0.125 \mu \mathrm{g} / \mathrm{ml}$, while the last tube was left without antibiotic as control. The prepared test tubes were incubated at $33^{\circ} \mathrm{C}$ for $24 \mathrm{~h}$. MIC was determined as the lowest concentration at no visible bacterial growth.

\section{Treatment experiment}

Drug

Alamycin $300^{\circledR}$ (Norbrook Co., United Kingdom) long-acting solution contains OTC dihydrate $30 \mathrm{mg} / \mathrm{ml}$.

\section{Fish grouping}

Twenty clinically diseased $D$. sargus were randomly divided into two equal groups, each containing 10 fish; Group 1 was treated with Alamycin 300 at a dose of $100 \mathrm{mg} / \mathrm{kg}$ body weight by intraperitoneal injection, and Group 2 remains as a control. Each group was kept in 2000-L fiberglass tank supplied with marine water $35 \%$ with continuous aeration. The temperature was thermostatically controlled at $25^{\circ} \mathrm{C}$ and fish were observed for 14 days from the first dose.

Determination of OTC in fish serum by

high-performance liquid chromatography (HPLC)

Ten healthy $D$. sargus were used in this experiment; each fish was inoculated with Alamycin $300^{\circledR}$ at a dose of $100 \mathrm{mg} / \mathrm{kg}$ body weight. Fish were kept in a fiberglass tank at which water temperature was thermostatically adjusted at $25^{\circ} \mathrm{C}$, and then $500 \mu \mathrm{l}$ blood was collected through the caudal vessels from each fish at $24,48,72,96,120,144$, and 168-h post-injection. The serum was separated by centrifuge at $5000 \mathrm{rpm}$ and then was stored at $-23^{\circ} \mathrm{C}$. OTC concentration was determined in serum samples according to the method described by Lei et al. [25] using Nexera X2 HPLC system, Shimadzu, Japan, and C18 reverse-phase column, Zorbax SB-C18 $5.0 \mu \mathrm{m}$, $4.6 \mathrm{~mm} \times 250 \mathrm{~mm}$, Agilent, USA. The mobile phase consisted of $0.01 \mathrm{~mol} / \mathrm{l}$ oxalic acid, methanol, and acetonitrile with a volume ratio of $83: 7: 10$, respectively. OTC level was detected at 355-nm wavelength.

\section{Results}

\section{Antemortem and postmortem inspection}

The inspections show hemorrhagic skin ulcers of different degrees (starting with scale desquamation, hyperemia, followed by deep hemorrhagic skin ulcers reaching the deep musculature), unilateral exophthalmia, fin erosions, and hemorrhagic tail with severe erosions (Figure-1a and b). Congested hepatopancreas and kidney were the most prominent PM lesion. The recorded mortality was estimated by $38.33 \%$ ( 23 of 60 fish).

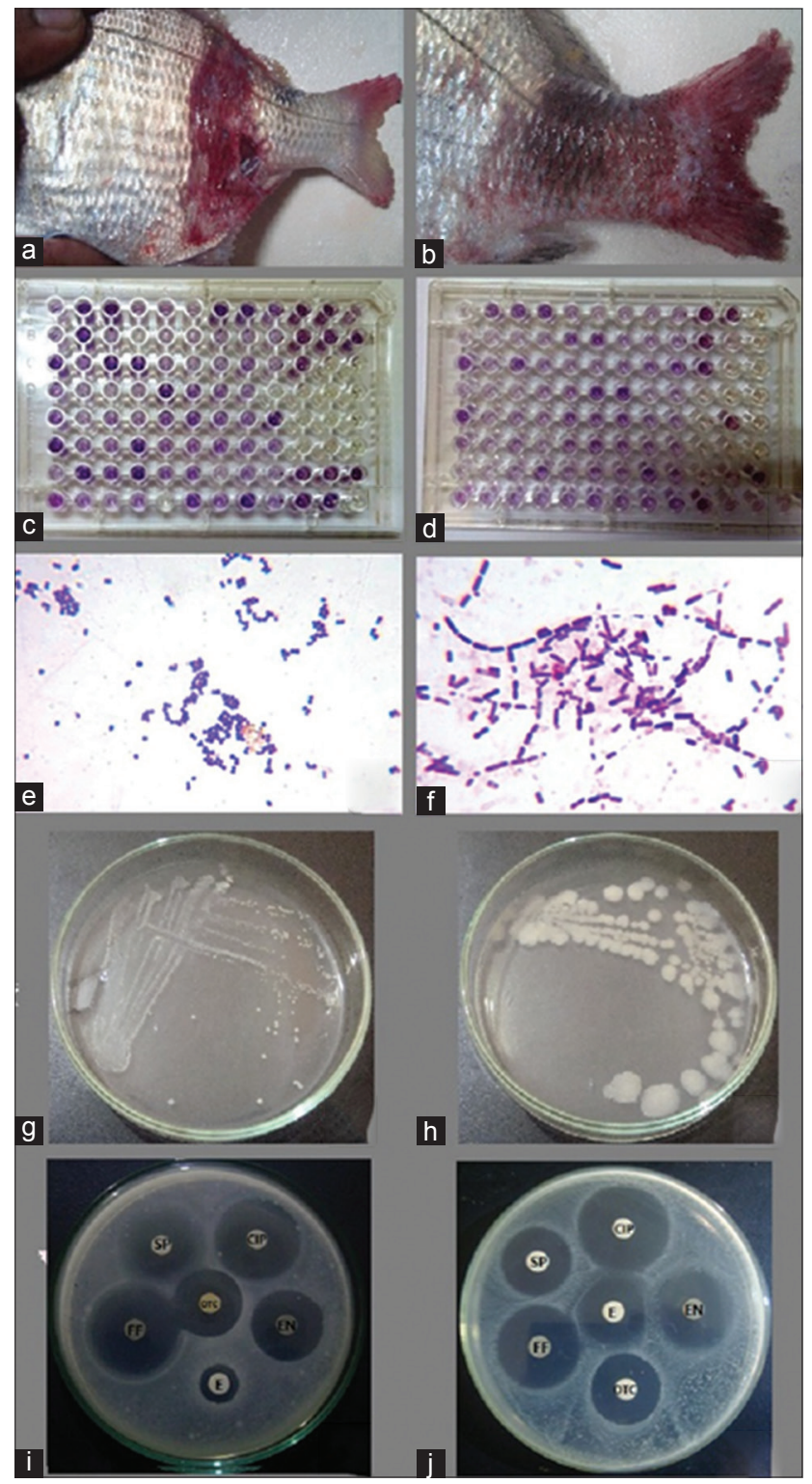

Figure-1: ( $a$ and b) Naturally infected white sea bream (Diplodus sargus) showing scale desquamation, skin ulceration even complete loss of skin, and appearance of musculature with congestion and hemorrhage in caudal peduncle together with tail erosion and hemorrhages. (c and d) Biolog GEN III microplate showing the biochemical profile of Staphylococcus epidermidis (c) and Bacillus cereus (d). (e) Gram-stained S. epidermidis appeared as Grampositive cocci, 0.65-0.91 $\mu \mathrm{m}$ in diameter, present as single, pairs, and clusters. (f) Gram-stained B. cereus appeared as Gram-positive spore-forming long bacilli, 4.97-7.48 $\mu \mathrm{m}$ in length and 1.58-1.64 in width, arranged in short or long chains. (g) S. epidermidis colonies on Tryptic Soy Agar appeared as white pinpoint colonies about 0.2-1 $\mathrm{mm}$ in diameter.)h) B. cereus colonies on Tryptic Soy Agar appeared as large white granular colonies with irregular perimeters about $1.5-5 \mathrm{~mm}$ in diameter. (i) Antibiogram indicated the sensitivity of $B$. cereus to oxytetracycline (OTC), ciprofloxacin (CIP), enrofloxacin (ENR), florfenicol (F), and spiramycin (SP), while it resists erythromycin (E). (j) Antibiogram indicated the sensitivity of $S$. epidermidis to OTC, CIP, ENR, F, SP, and E. 


\section{Results of bacterial isolation and identification}

Twenty-six Gram-positive isolates were recovered from nine moribund fish; 15 isolates were cocci, and 11 were bacilli (Table-1).

Biolog microbial identification system illustrates the presence of 15 S. epidermidis (Figure-1c) and 11 Bacillus cereus isolates (Figure-1d).

\section{Culture characters of the recovered bacteria}

$S$. epidermidis appeared as white pinpoint colonies about $0.2-1 \mathrm{~mm}$ in diameter (Figure-1g), while $B$. cereus appeared as large white granular colonies with irregular perimeters about $1.5-5 \mathrm{~mm}$ in diameter (Figure-1h).

\section{Morphological characteristics of the recovered bacteria}

S. epidermidis appeared as Gram-positive cocci ranged between 0.65 and $0.91 \mu \mathrm{m}$ in diameter, and it was present as single, pairs, and clusters (Figure-1e), while $B$. cereus appeared as Gram-positive rods present in short or long chains, and each bacillus was 4.97$7.48 \mu \mathrm{m}$ in length and 1.58-1.64 in width (Figure-1f).

$S$. epidermidis was isolated from the heart, tail, muscle, and eye, while $B$. cereus isolate was isolated from the tail, muscle, and eye as shown in Table-1.

\section{Results of the histopathological examination}

The histopathological study of naturally infected $D$. sargus tissues revealed the presence of different pathological alterations (Figure-2). Hepatopancreas tissue lost their normal architecture with the presence of inflammatory reaction manifested in mononuclear cell infiltration, necrotic areas were also present, hepatic tissue congestion expressed as congested hepatic sinusoids, and distended blood vessels engorged with erythrocytes (Figure-2a-c). Posterior kidney tissue was severely affected as glomerular hypertrophy with narrowed Bowman's space was present. Some degenerated shrinkage glomerular tuft was also observed. Furthermore, renal tubules were involved in this degenerative changes in which detachment of tubular epithelium was observed. Inflammation of renal tissue was presented as interstitial mononuclear cell infiltration and melanomacrophage center activation (Figure-2d-f). Exophthalmic tissue examination indicated marked separation between retina layers, especially pigment epithelium and the photoreceptor layers, as these tissues appeared corrugated (Figure-2g). Ulcerated skin lesions show destruction of epidermis that was completely lost with exposure of

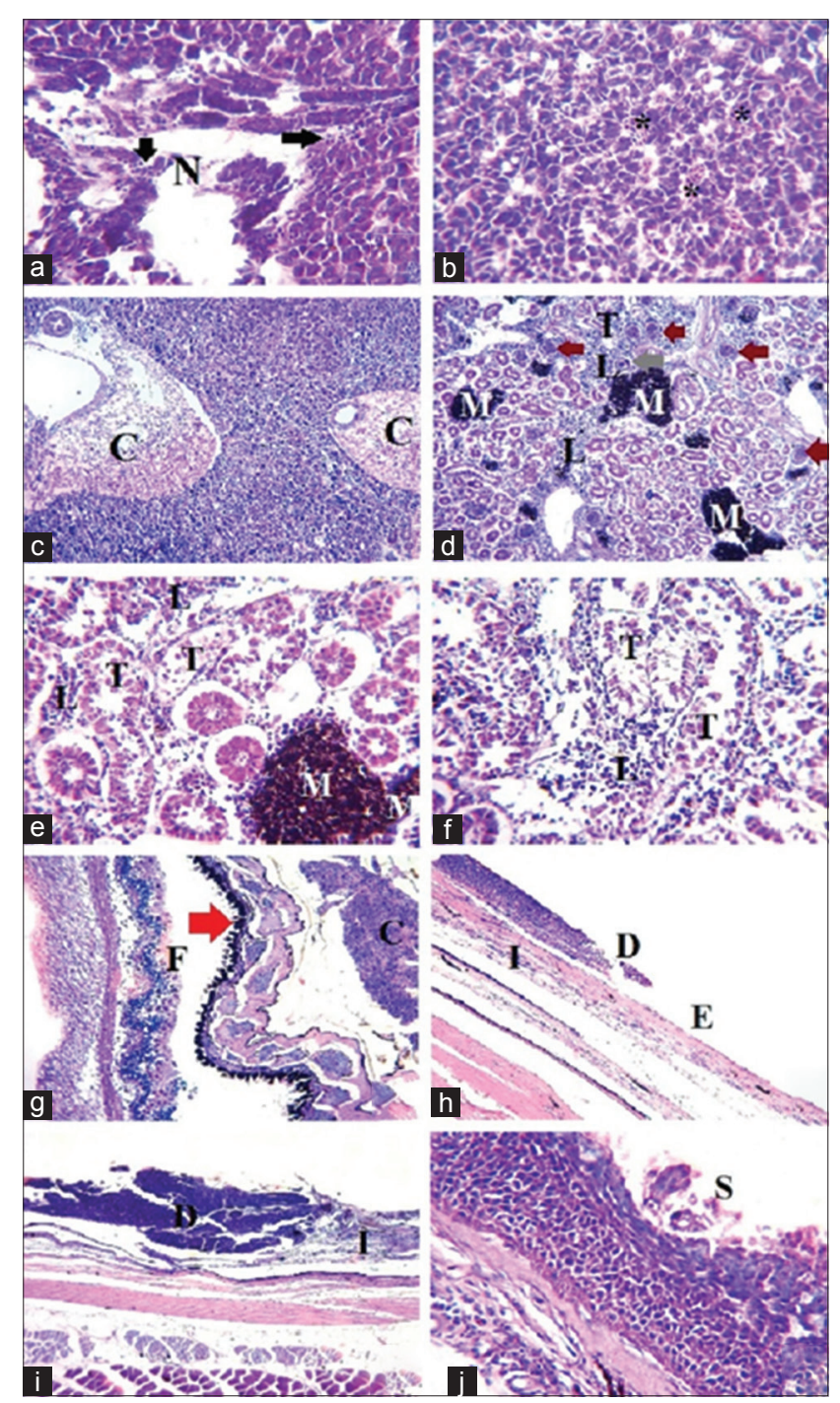

Figure-2: Histopathologicallesionsinduced by Staphylococcus epidermidis and Bacillus cereus infection in affected white sea bream (Diplodus sargus). (a-c) Hepatopancreas showing loss of normal tissue architecture, presence of necrotic areas (N) with mononuclear cell infiltration (arrow), congested hepatic sinusoids (*) and congested distended blood vessels (C), hematoxylin and eosin $(H$ and $E), X=400$ in ( $a$ and $b)$ and 100 in (c). (d-f) Posterior kidney showing glomerular hypertrophy with narrow Bowman's space (brown arrow), degenerated shrinkage glomerular taught (gray arrow), detached tubular epithelium $(T)$, interstitial mononuclear cell infiltration $(L)$, melanomacrophage centers activation (M), $H$ and $E, X=100$ in (d) and 100 in (e and f). (g) Eye with marked separation between retina layers, especially, pigment epithelium layer (red arrow) which also is corrugated and the photoreceptor layer (F), (C) is the choroid body, $H$ and $E, X=100$. (h-j) Skin showing destruction of epidermis even complete loss (D) with exposure of dermis (E) and presence of leukocytic infiltration (I), in less affected cases loss of the superficial layer of the stratified squamous epithelium (S), $H$ and $E$, $X=100$ in (h and $i$ ) and 400 in (j).

Table-1: Number of Staphylococcus epidermidis and Bacillus cereus isolates from each organ of diseased white sea bream (Diplodus sargus) broodstock.

\begin{tabular}{|c|c|c|}
\hline Organ of isolation & Number of Staphylococcus epidermidis isolates & Number of Bacillus cereus isolates \\
\hline Muscle & 5 & 5 \\
\hline Eye & 1 & 1 \\
\hline Heart & 4 & 0 \\
\hline Tail & 5 & 5 \\
\hline Total & 15 & 11 \\
\hline
\end{tabular}


dermis and presence of leukocytic infiltration, but, in less affected cases, the superficial layer of the stratified squamous epithelium was eroded (Figure-2h-j).

\section{Antibiotic sensitivity test results}

S. epidermidis was sensitive to OTC, CIP, ENR, F, SP, and E (Figure-1j), while B. cereus was sensitive to all mentioned antibiotics except $\mathrm{E}$ (Figure-1i) as presented in Table- 2 .

\section{The MIC of OTC}

Twenty out of 26 isolates resembling 9 S. epidermidis and all the $11 \mathrm{~B}$. cereus were highly susceptible to OTC with MIC ranged between $<0.12$ and $4 \mu \mathrm{g} / \mathrm{ml}$, while two $S$. epidermidis isolates were intermediately susceptible with MIC equal to $8 \mu \mathrm{g} / \mathrm{ml}$, but four isolates were resistant with MIC equal to $16-32 \mu \mathrm{g} / \mathrm{ml}$ (Table-3).

\section{Results of treatment trial}

Treated fish showed gradual improvement starting with disappearance of hyperemia and hemorrhage from tail and skin ulcers at the $2^{\text {nd }}$-day post-treatment followed by partial healing of ulcers throughout the $1^{\text {st }}$ week. The cumulative mortality during 2 weeks after treatment was $40 \%$ in infected non-treated group but was only $10 \%$ in the treated group as one severely ulcerated fish died at the $2^{\text {nd }}$ day post-treatment.

\section{OTC level in fish serum following intraperitoneal inoculation}

OTC level in D. sargus serum reached $34.57 \pm 1.09, \quad 25.98 \pm 0.96, \quad 20.39 \pm 1.2, \quad 13.10 \pm 0.32$, $10.04 \pm 0.26,7.68 \pm 0.42$, and $5.14 \pm 0.23(\mu \mathrm{g} / \mathrm{ml})$ at 24 , $48,72,96,120,144$, and $168 \mathrm{~h}$, respectively, following the intraperitoneal injection as presented in Table- 4 .

\section{Discussion}

Introduction of a new species is an essential element for expansion in marine culture; White Sea bream (D. sargus) is an excellent candidate for this purpose as it has good acceptability for consumers; and increased fry (seeds) production is an essential element for sustainable aquaculture.

Streptococci considered a potential cause of diseases in mariculture [26]. S. epidermidis is considered

Table-2: Antibiotics susceptibility test results for Staphylococcus epidermidis and Bacillus cereus.

\begin{tabular}{|c|c|c|c|c|}
\hline \multirow[t]{2}{*}{ Antibiotic } & \multicolumn{2}{|c|}{ Staphylococcus epidermidis } & \multicolumn{2}{|c|}{ Bacillus cereus } \\
\hline & Inhibition zone $\mathrm{mm}$ & Interpretation & Inhibition zone $\mathrm{mm}$ & Interpretation \\
\hline OTC $30 \mu \mathrm{g}$ & 22 & Susceptible & 21 & Susceptible \\
\hline CIP $5 \mu \mathrm{g}$ & 27 & Susceptible & 26 & Susceptible \\
\hline ENR $5 \mu \mathrm{g}$ & 24 & Susceptible & 22 & Susceptible \\
\hline $\mathrm{F} 10 \mu \mathrm{g}$ & 24 & Susceptible & 27 & Susceptible \\
\hline $\mathrm{SP} 100 \mu \mathrm{g}$ & 21 & Susceptible & 17 & Susceptible \\
\hline $\mathrm{E} 15 \mu \mathrm{g}$ & 19 & Susceptible & 11 & Resistant \\
\hline
\end{tabular}

OTC=Oxytetracycline, CIP=Ciprofloxacin, ENR=Enrofloxacin, F=Florfenicol, SP=Spiramycin, E=Erythromycin

Table-3: MIC of oxytetracycline.

\begin{tabular}{lccl}
\hline Bacterial strain & Isolate Number & MIC of oxytetracycline $\boldsymbol{\mu g} / \mathbf{m l}$ & Interpretation \\
\hline Staphylococcus epidermidis & 1 & $<0.125$ & Susceptible \\
& 2 & 16 & Resistant \\
Resistant & Intermediate \\
& 3 & 32 & Resistant \\
& 4 & 8 & Susceptible \\
Resistant & Intermediate \\
Bacillus cereus & 5 & 0.5 & Susceptible \\
& 7 & 32 & Susceptible \\
& 8 & 8 & Susceptible \\
& 9 & 4 & Susceptible \\
& 10 & $<0.125$ & Susceptible \\
& 12 & 4 & Susceptible \\
& 13 & 0.125 & Susceptible \\
& 14 & 0.5 & Susceptible \\
& 15 & 0.125 & Susceptible \\
& 1 & 4 & Susceptible \\
& 2 & $<0.125$ & Susceptible \\
& 3 & $<0.125$ & Susceptible \\
& 4 & 2 & Susceptible \\
& 5 & 125 & Susceptible
\end{tabular}

Interpretation: Susceptible $\leq 4$, Intermediate $=8$, Resistant $\geq 16 \mu \mathrm{g} / \mathrm{ml}$. MIC=Minimum inhibitory concentration 
Table-4: Oxytetracycline levels in the serum of white sea bream (Diplodus sargus) broodstock at different time points post-treatment.

\begin{tabular}{lc}
\hline $\begin{array}{l}\text { Sampling time } \\
\text { (h postinjection) }\end{array}$ & $\begin{array}{c}\text { Oxytetracycline } \\
\text { level }(\boldsymbol{\mu g} / \mathbf{m l})\end{array}$ \\
\hline 24 & $34.57 \pm 1.09$ \\
48 & $25.98 \pm 0.96$ \\
72 & $20.39 \pm 1.2$ \\
96 & $13.10 \pm 0.32$ \\
120 & $10.04 \pm 0.26$ \\
144 & $7.68 \pm 0.42$ \\
168 & $5.14 \pm 0.23$ \\
\hline
\end{tabular}

$\mathrm{n}=6$, values are mean \pm standard error

a potential fish pathogen as it can lead to localized, as well as systemic, infection in cultured fresh and marine fish species [27-29]. Infections with $B$. cereus were also recorded by Baya et al. [30] and Chandra et al. [31] in striped bass and stinging catfish, respectively.

In the current study, D. sargus broodstock suffered from increased mortality that was estimated by $38.33 \%$. Diseased fish showed deep skin ulcers that reached the musculature, hemorrhages, fin and tail erosions, and exophthalmia with congested parenchymatic organs (hepatopancreas and posterior kidney), and similarly, anti- and post-mortem lesions were recorded by Golomazou et al. [3] in diseased caged white sea bream. Kubilay and Uluköy [32] isolated $S$. epidermidis from diseased gilthead sea bream (Sparus aurata) with hemorrhages on gills, skin, and fins, and Kusuda and Sugiyama [33] isolated S. epidermidis from diseased yellowtail (Seriola quinqueradiata) and red sea bream (Chrysophrys major) that showed exophthalmia, swelling, and congestion of caudal peduncle, these observations were identical to the present work findings. Chandra et al. [31] reported nearly similar signs in stinging catfish. Heteropneustes fossilis infected with $B$. cereus. Parallel to the current findings Austin [34] cited the presence of generalized necrotizing dermatitis in $B$. cereus-infected fish. Aboyadak et al. [7] recorded similar clinical signs and postmortem lesions in sea bass infected with $B$. cereus and S. epidermidis.

The histopathological examination indicated the presence of some pathological lesions involving hepatopancreas as inflammation, congestion, and necrosis. Posterior kidney showed degenerated glomeruli and renal tubules with inflammatory cell aggregation. These findings were supported by Austin [34], who reported the presence of focal necrosis and petechial hemorrhages in the liver and kidney of $B$. cereus-infected fish. Marked separation between retina layers especially pigment epithelium and the photoreceptor layer of affected eye which could have resulted from the increased intraocular pressure.

The ante- and post-mortem findings together with the histopathological lesions indicated the severity of the current infection affecting $D$. sargus broodstock and it is mainly induced by different virulence factors produced by the isolated causative agents, especially in stressed broodstock that suffered from frequent handling and hormonal treatment (injection) which is accompanied with scales detachment and skin abrasions that act as a porter of entry for pathogenic and opportunistic bacteria.

$S$. epidermidis is not considered a part of normal fish flora as it has many virulence factors responsible for its pathogenicity. They are mainly extracellular products as proved by Huang et al. [27], who found that inoculation of tilapia with filter-sterilized culture broth of $S$. epidermidis causes similar mortality as bacterial suspension contains $1.34 \times 10^{9} \mathrm{CFU} / \mathrm{ml}$. Namvar et al. [35] mentioned some virulence factors of $S$. epidermidis as biofilm formation, polysaccharide intercellular adhesion, surface adhesion protein, poly- $\gamma$-glutamic acid (responsible for phagocytosis inhibition), toxins as staphylococcal enterotoxin-like toxin, and delta toxin. Pinheiro et al. [36] recorded that $S$. epidermidis exhibits high toxigenic potential as they identified eight enterotoxin genes from 85 clinical isolates.

$B$. cereus has many virulence factors, including hemolysin, which have a dermonecrotic and vascular permeability activity [37]. Prasad [38] isolated enterotoxigenic $B$. cereus from 10 marine fish guts. $B$. cereus is known to produce substances responsible for virulence including hemolysins (I, II, and III), enterotoxins, cytotoxin $\mathrm{K}$, and phospholipase which in combination induce the disease condition [39]. B. cereus is famous as foodborne poisoning microorganism, but it is also considered the causative agent of many other serious diseases such as endocarditis, ocular infection, myonecrosis and cutaneous infections, nosocomial infections, meningitis, and urinary tract infection [40-44].

S. epidermidis grown as white pinpoint colonies (0.2-1 $\mathrm{mm}$ in diameter), morphologically present as Gram-positive cocci $0.65-0.91 \mu \mathrm{m}$ in diameter which was identical to that described by Huang et al. [27] and Kusuda and Sugiyama [33] for S. epidermidis isolated from clinically diseased fish.

$B$. cereus colonies were large white granular with irregular perimeters, about $1.5-5 \mathrm{~mm}$ in diameter, B. cereus appeared as Gram-positive spore-forming long bacilli, 4.97-7.48 $\mu \mathrm{m}$ in length and 1.58-1.64 in width, arranged in short or long chains that are similar to the description reported by Bottone [45].

The recovered $S$. epidermidis isolates were sensitive to CIP, ENR, F, SP, and E, but only four isolates resisted OTC. These results are in complete harmony with Kusuda and Sugiyama [33] as they reported its sensitivity to OTC, chloramphenicol, and E, but it partially agrees with that of Kubilay and Uluköy [32] as they recorded $S$. epidermidis sensitivity to CIP, ENR, and chloramphenicol, while it was resistant to OTC and E. Sergelidis et al. [46] recorded the sensitivity of S. epidermidis isolated from fish to quinolones and its resistance to $\mathrm{E}$. 
B. cereus isolates were sensitive to OTC, CIP, ENR, F, and SP, but they resisted E. This result was compatible with that done by Chandra et al. [31] except for OTC. Weber et al. [47] also reported the sensitivity of $B$. cereus to chloramphenicol, CIP, and tetracycline. The mentioned difference in antibiotic susceptibility profile of $S$. epidermidis and B. cereus isolates could be attributed to the presence of certain antibiotic resistance genes.

OTC is currently available and approved by the U.S. Food and Drug Administration for use as a chemotherapeutic agent in food fish [48]. Intraperitoneal administration of long-acting OTC at a dose of $100 \mathrm{mg} / \mathrm{kg}$ body weight was very effective in termination of the present infection as the mortality rate decreases from $40 \%$ in infected non-treated group to $10 \%$ in infected treated group, together with disappearance of hemorrhage and congestion followed by regenerative changes as ulcer healing, regrowth of eroded fins, and tail. Only one fish died in the treated group, which may have resulted from the presence of large ulcers on its body before treatment. It was severely affected by bacterial invasion and toxins or due to osmoregulation failure.

The successfulness of the treatment is not only reflecting the proper selection of antibiotic, but also the drug formulation has a role as long-acting formula administrated once (each fish handled once to decrease the stress and ulceration during manipulation), as well. Parenteral administration has many advantages over oral drug administration: Diseased fish became off-food, on the other hand, some interfering substances which may present in water as ions can inactivate, chelate, or decrease the concentration of the orally administrated drug.

Sensitivity test indicated the high susceptibility of $S$. epidermidis and B. cereus isolates to OTC, also, the low MIC accelerates the response to the treatment, although there were four $S$. epidermidis isolates having MIC of 16 and $32 \mu \mathrm{g} / \mathrm{ml}$. That means these isolates resist OTC, but the treatment was successful, and this can be explained by increasing the serum concentration over $32 \mu \mathrm{g} / \mathrm{ml}$, and at this point, OTC became effective.

Serum OTC level reaches $34.57 \pm 1.09 \mu \mathrm{g} / \mathrm{ml}$ at $24 \mathrm{~h}$ post-drug administration, and then, it remains over $5 \mu \mathrm{g} / \mathrm{ml}$ on the $7^{\text {th }}$ day, which indicates the efficacy of single intraperitoneal inoculation in protection and treatment against susceptible pathogens for at least 7 consecutive days. Nearly similar result was recorded by Bowden [49], who found that OTC remains over $4 \mu \mathrm{g} / \mathrm{ml}$ after 168 -h post-intramuscular or intraperitoneal administration in yellow perch (Perca flavescens), while Rigos et al. [16] determined the 24-h OTC plasma concentration as $18 \mu \mathrm{g} / \mathrm{ml}$ after intramuscular administration of $50 \mathrm{mg} / \mathrm{kg}$ in healthy grouper (Epinephelus marginatus) which differs from our findings, due to the difference in the used dose.

\section{Conclusion}

Single intraperitoneal injection of long-acting OTC at a dose of $100 \mathrm{mg} / \mathrm{kg}$ body weight was effective in termination of $S$. epidermidis and B. cereus infection in white sea bream (D. sargus) broodstock.

\section{Authors' Contributions}

NGMA: designed the study, performed clinical and postmortem examination and bacterial isolation and identification, also performed the histopathological examination and wrote the manuscript. IMA: designed and conducted the treatment trial, sensitivity test, and HPLC analysis and helped in manuscript writing and preparations. HSE: fish sampling, rearing, and observation. All authors read and approved the final manuscript.

\section{Acknowledgment}

The authors thank Science and Technology Development Fund, Ministry of Higher Education and Scientific Research, Egypt, for supporting this research through project number 26275, entitled "Isolation and identification of viral, bacterial and parasitic etiological agents responsible for outbreaks affecting cultured marine fishes in Damietta governorate with establishing of control strategies."

\section{Competing Interests}

The authors declare that they have no competing interests.

\section{Publisher's Note}

Veterinary World remains neutral with regard to jurisdictional claims in published institutional affiliation.

\section{References}

1. Zhou, X. (2017) An Overview of Recently Published Global Aquaculture Statistics, in FAO Aquaculture Newsletters, Proceedings No. 56, Switzerland.

2. OECD/FAO. (2016) OECD-FAO Agricultural Outlook 2016-2025. OECD Publishing, Paris. Available from: http://www.dx.doi.org/10.1787/agr_outlook-2016-en. Last accessed at 1/10/2018.

3. Golomazou, E., Athanassopoulou, F., Vagianou, S., Sabatakou, O., Tsantilas, H., Rigos, G. and Kokkokiis, L. (2006) Diseases of White Sea bream (Diplodus sargus L.) Reared in experimental and commercial conditions in Greece. Turk. J. Vet. Anim. Sci., 30(1): 389-396.

4. Sa, R., Pousao-Ferreira, P. and Oliva-Teles, A. (2008) Effect of dietary starch source (normal versus waxy) and protein levels on the performance of white sea bream Diplodus sargus (Linnaeus) juveniles. Aquac. Res., 39(10): 1069-1076.

5. Pridgeon, J.W. and Klesius, P.H. (2012) Major bacterial diseases in aquaculture and their vaccine development. $C A B$ Rev., 7(48): 1-16.

6. Lafferty, K.D., Harvell, C.W., Conrad, J.M., Friedman, C.S., Kent, M.L., Kuris, A.K., Powell, E.N., Rondeau, D. and Saksida, S.M. (2015) Infectious diseases affect marine fisheries and aquaculture economics. Ann. Rev. Mar. Sci., 7(2015): 471-496.

7. Aboyadak, I.M. Sabry, N.M., Ali, N.G. and El-Sayed, H.S. (2016) Isolation of Staphylococcus epidermidis, Bacillus cereus and Pseudomonas stutzeri from diseased European 
sea bass (Dicentrarchus labrax) for the first time in Egypt. Egypt. J. Aquat. Biol. Fish., 20(4): 103-114.

8. Austin, B. and Newaj-Fyzul, A. (2017) Diagnosis and Control of Diseases of Fish and Shellfish. John Wiley and Sons Ltd., CPI Group (UK) Ltd., Croydon.

9. Sudheesh, P.S., Al-Ghabshi, A., Al-Mazrooei, N. and Al-Habsi, S. (2012) Comparative pathogenomics of bacteria causing infectious diseases in fish. Int. J. Evol. Biol., 2012(1): 457264.

10. Al Bulushi, I.M., Poole, S.E., Barlow, R., Deeth, H.C. and Dykes, G.A. (2010) Speciation of Gram-positive bacteria in fresh and ambient-stored sub-tropical marine fish. Int. J. Food Microbiol., 138(1-2): 32-38.

11. Abdelaziz, M., Ibrahem, M.D., Ibrahim, M.A., Abu-Elala, N.M. and Abdel-Moneam, D.A. (2017) Monitoring of different Vibrio species affecting marine fishes in Lake Qaroun and Gulf of Suez: Phenotypic and molecular characterization. Egypt. J. Aquat. Res., 43(2): 141-146.

12. Kalatzis, P.G., Castillo, D., Katharios, P. and Middelboe, M. (2018) Bacteriophage Interactions with marine pathogenic Vibrio: Implications for phage therapy. Antibiotics, 7(1), e15.

13. Nasreldin, E. (2018) Clonal relationship among the Vibrio parahaemolyticus isolates from coastal water in Saudi Arabia. Egypt. J. Aquat. Res., 44(2): 131-137.

14. Shargel, L. and Yu, A.B.C. (2015) Introduction to biopharmaceutics and pharmacokinetics. In: Applied Biopharmaceutics and Pharmacokinetics. $7^{\text {th }}$ ed. McGrawHill Education, New York.

15. Buxton, I.L.O. and Benet, L.Z. (2011) Pharmacokinetics: The dynamics of drug absorption, distribution, metabolism, and elimination. In: Brunton, L.L., Chabner, B.A. and Knollmann, B.C., editors. Goodman and Gilman's Pharmacological Basis of Therapeutics. 12 $2^{\text {th }}$ ed. The McGraw-Hill Companies, New York.

16. Rigos, G., Katharios, P. and Papandroulakis, N. (2010) Single intramuscular administration of long-acting oxytetracycline in grouper (Epinephelus marginatus). Turk. J. Vet. Anim. Sci., 34(5): 441-445.

17. NACLAR. (2004) National Advisory Committee for Laboratory Animals Research. 20 Biopolis Way \#08-01 Centros Singapore 138668. Available from: http://www. research.ntu.edu.sg/guides/Documents/Ethics/NACLARguide $\% 20$ Lines.pdf. Last accessed at 10/10/2018.

18. CCAC. (2005), Guidelines On: The Care and Use of Fish in Research, Teaching and Testing. Canadian Council on Animal Care, Guidelines Program. Ottawa, Canada. p1510-130.

19. Stoskopf, K.M. (2010) Fish Medicine. $2^{\text {nd }}$ ed. ART Sciences LLC, 3512 Olive Chapel Road Extension Apex, North Carolina. p125-151.

20. Aboyadak, I.M., Ali, N.G.M., Goda, A.M.A., Saad, W. and Salam, A.M.E. (2017) Non-Selectivity of R S Media for Aeromonas hydrophila and TCBS Media for Vibrio Species isolated from diseased Oreochromis niloticus. J. Aquac. Res. Dev., 8(496): 1-5.

21. Black, J.G. and Black, L.J. (2015) Microbiology: Principles and Explorations. $9^{\text {th }}$ ed. John Wiley and Sons, Inc., Hoboken.

22. Suvarna, S.K., Layton, C. and Bancroft, J.D. (2018) Bancroft's Theory and Practice of Histological Techniques. $8^{\text {th }}$ ed. United Kingdom: Elsevier Limited.

23. CLSI. (2015) Performance Standards for Antimicrobial Susceptibility Testing; Twenty-Fifth Informational Supplement. CLSI document M100-S25. Clinical and Laboratory Standards Institute, Wayne, PA.

24. Hack, D.M., Dressel, D.C. and Peterson, L. (1999) Highly reproducible bactericidal activity test results by using a modified national committee for clinical laboratory standards broth macrodilution technique. J. Clin. Microbiol., 37(6): 1881-1884.

25. Lei, Z., Liu, Q., Yang, B., Ahmed, S., Xiong, J., Song, T., Chen, P., Cao, J. and He, Q. (2017) Evaluation of bioequivalence of two long-acting $20 \%$ oxytetracycline formulations in pigs. Front. Vet. Sci., 4(61): 1-6.

26. Toranzo, A.E., Magarĩnos, T.B. and Romalde, J.L. (2005) A review of the main bacterial fish diseases in mariculture systems. Aquaculture, 246(1-4): 37-61.

27. Huang, S.L., Chen, W.C., Shei, M.C., Liao, I.C. and Chen, A.N. (1999) Studies on epizootiology and pathogenicity of Staphylococcus epidermidis in tilapia (Oreochromis Spp.) cultured in Taiwan. Zool. Stud., 38(2): 178-188.

28. Yiagnisis, M. and Athanassopoulou, F. In: Aral, F., editor. (2011) Bacteria Isolated from Diseased Wild and Farmed Marine Fish in Greece, Recent Advances in Fish Farms. InTech Europe, University Campus STePRi, SlavkaKrautzeka 83/A, 51000 Rijeka, Croatia.

29. Buller, N.B. (2014) Bacteria and Fungi from Fish and Other Aquatic Animals. $2^{\text {nd }}$ ed. CABI, Nosworthy Way, Wallingford, Oxfordshire.

30. Baya, A., Li, T., Lupiani, B. and Hetrick, F.M. (1992) Bacillus cereus, a Pathogen for Striped Bass. In: Eastern Fish Health and American Fisheries Society Fish Health Section Workshop, 16-19 June 1992. Auburn University, Auburn, Alabama. p67.

31. Chandra, G., Bhattacharjee, I. and Chatterjee, S. (2015) Bacillus cereus infection in stinging catfish, Heteropneustes fossilis (Siluriformes: Heteropneustidae) and their recovery by Argemone mexicana seed extract. Iran. J. Fish. Sci., 14(3): 741-753.

32. Kubilay, A. and Uluköy, G. (2004) First isolation of Staphylococcus epidermidis from cultured gilthead sea bream (Sparus aurata) in Turkey. Bull. Eur. Ass. Fish. Pathol., 24(3): 137-143.

33. Kusuda, R. and Sugiyama, A. (1981) Studies on characters of Staphylococcus epidermidis isolated from diseased fishes, on the morphological, biological, and biochemical properties. Fish Pathol., 16(1): 15-24.

34. Austin, B. (1999) Emerging bacterial fish pathogen. Bull. Eur. Ass. Fish. Pathol., 19(6): 231-234.

35. Namvar, A.E., Bastarahang, S., Abbasi, N., Ghehi, G.S., Farhadbakhtiarian, S., Arezi, P., Hosseini, M., Baravati, S.Z., Jokar, Z. and Chermahin, S.G. (2014) Clinical characteristics of Staphylococcus epidermidis: A systematic review. GMS Hyg. Infect. Control., 9(3): Doc23.

36. Pinheiro, L., Brito, C.I., Oliverra, A.D., Martins, P.Y.F., Pereira, V.C. and Cunha, M.D. (2015) Staphylococcus epidermidis and Staphylococcus haemolyticus: Molecular detection of cytotoxic and enterotoxin genes. Toxins, 7(9): 3688-3699.

37. Granum, P.E. and Lund, T. (1997) Bacillus cereus and its food poisoning toxins. FEMS Microbiol. Lett., 157(2): 223-228.

38. Prasad, M.P. (2014) Molecular characterization of enterotoxigenic Bacillus cereus species isolated from tropical marine fishes using RAPD markers. Int. J. Pure. Appl. Biosci., 2(4): 189-195.

39. Visiello, R., Colombo, S. and Carretto, E. (2016) Bacillus cereus hemolysins and other virulence factors. In: Savini, V., editor. The Diverse Faces of Bacillus cereus. Academic Press is an Imprint of Elsevier, London Wall, London. p35-44

40. Steen, M.K., Bruno-Murtha, L.A., Chaux, G., Lazar, H., Bernard, S. and Sulis, C. (1992) Bacillus cereus endocarditis: Report of a case and review. Clin. Infect. Dis., 14(4): 945-946.

41. Callegan, M.C., Booth, M.C., Jett, B.D. and Gilmore, M.S. (1999) Pathogenesis of gram-positive bacterial endophthalmitis. Infect. Immun., 67(7): 3348-3356.

42. Darbar A., Harris I.A., Gosbell. I.B. (2005) Necrotizing infection due to Bacillus cereus mimicking gas gangrene following penetrating trauma. J. Orthop. Trauma., 19(5): 353-355.

43. Auger, S., Ramarao, N., Faille, C., Fouet, A., Aymerich, S. and Gohar, M. (2009) Biofilm formation and cell surface 
properties among pathogenic and nonpathogenic strains of the Bacillus cereus group. Appl. Environ. Microbiol., 75(20): 6616-6618.

44. Lebessi, E., Dellagrammaticas, H.D., Antonaki, G., Foustoukou, M. and Iacovidou, N. (2009) Bacillus cereus meningitis in a term neonate. J Matern. Fetal Neonatal. Med., 22(5): 458-461.

45. Bottone, E.J. (2010) Bacillus cereus, a volatile human pathogen. Clin. Microbiol. Rev., 23(2): 382-398.

46. Sergelidis, D., Abrahim, A., Papadopoulos, T., Soultos, N., Martziou, E., Koulourida, A., Govaris, A., Pexara, A., Zdragas, A. and Papa, A. (2014) Isolation of methicillin-resistant Staphylococcus spp. From ready-to-eat fish products. Lett. Appl. Microbiol., 59(5): 500-506.

47. Weber, D.J., Saviteer, S.M. Rutala, W.A. and Tomann, C.A.
(1988) In vitro susceptibility of Bacillus spp. To selected antimicrobial agents. Antimicrob. Agents Chemother., 32(5): 642-645.

48. Miller, R.A. (2007) Development of Standardized Antimicrobial Susceptibility Testing Methods and Aeromonas salmonicida Epidemiologic Cutoff Values for Antimicrobial Agents Used in Aquaculture. Ph. D. Thesis, University of Maryland, College Park, USA. p3.

49. Bowden, B.C. (2001) Pharmacokinetic Profiles of Oxytetracycline in Yellow Perch (Perca flavescens) as Determined by Plasma Concentration Following Different Routes of Administration. M. V. Sc. Thesis, Department of Biomedical Sciences and Pathobiology, Virginia-Maryland Regional College of Veterinary Medicine, USA.

$* * * * * * * *$ 